\title{
INTERFACES E DISTANCIAMENTOS ENTRE A HERMENÊUTICA DE HANS- GEORG GADAMER E PAUL RICOEUR ${ }^{1,2}$
}

Roberto Roque Lauxen (Unisinos) ${ }^{3}$

rrlauxen@yahoo.com.br

Resumo: Este artigo apresenta as interfaces de dois dos maiores representantes da hermenêutica contemporânea, Hans-Georg Gadamer e Paul Ricoeur. Sem a pretensão de reconstruir a gênese teórica das posições em litígio, analisa diferentes aspectos dela, apontando convergências e divergências. Após breve introdução (primeira parte), desenvolve, na segunda parte, de forma mais analítica, o cruzamento das posições dos interlocutores em sete tópicos principais. Na terceira parte assume um momento de distanciamento em relação à hermenêutica das tradições de Gadamer, por meio da mediação crítica de Hans Ineichen e Paul Ricoeur. Com eles sustentamos a necessidade da hermenêutica das tradições incluir a ideia de crítica e o diálogo com a linguística e a filosofia analítica, posição que converge em favor da hermenêutica crítica de Ricoeur que pretendemos destacar em sua contribuição específica em relação à hermenêutica das tradições de Gadamer.

Palavras-chave: Hermenêutica; Gadamer; Ricoeur; Crítica.

\section{INTRODUC̣̃̃O}

Podemos afirmar, sem sombra de dúvidas, que a magnitude de Hans-Georg Gadamer (1900-2002) e Paul Ricoeur (19132005) para a tradição hermenêutica pode ser comparada

\footnotetext{
${ }^{1}$ Recebido: 17-04-2011/Aprovado: 05-12-2011/Publicado on-line: 15-09-2012.

${ }^{2}$ Esta pesquisa tem o apoio da CAPES.

${ }^{3}$ Roberto Roque Lauxen é Doutor pela Faculdade de Filosofia da Universidade do Vale dos Sinos, RS, Brasil.
} 
com a de Husserl e Heidegger em relação à tradição fenomenológica. Na convergência dessa mesma tradição hermenêutica, Gadamer e Ricoeur possuem mais características complementares do que contrárias. Subtraindo alguns raros encontros ${ }^{4}$, a referência que cada um pôde fazer em relação ao outro foi sempre mediada pelo texto, mais ao modo ricoeuriano. Em vista disso, tornou-se uma tarefa para comentaristas reconstruir os fragmentos possíveis de um diálogo interrompido.

Uma das razões para esse distanciamento está no fato de que ambos combatiam em frentes diferentes e possuíam adversários distintos. Não sendo inimigos diretos, não tinham necessidade de enfrentamento. Embora Jean Grondin sustente que Gadamer tenha lido Ricoeur ${ }^{5}$, essas referências são praticamente nulas ${ }^{6}$. De outra parte, é evidente que Ricoeur leu Gadamer e fez várias referências diretas ao seu pensamento. Reconheceu essa dívida em várias ocasiões e talvez o tenha incorporado em seu próprio pensamento mais do que ele o tenha declarado em referências explícitas. Entre esses muitos reconhecimentos, Ricoeur (1995a, 80) declara, em sua Autobiografia Intelectual, que a obra de Gadamer Wahrheit und Methode "[...] se tornou para mim uma referência privilegiada”. Contudo, não é certo que a leitura que Ricoeur fez de Gadamer tenha sido fiel a

\footnotetext{
${ }^{4}$ Devemos registrar aqui o encontro de Ricoeur e Gadamer ocorrido nos Estados Unidos em 1982 (RICOUER; GADAMER 1991, 216-241).

"Gadamer conhece seguramente a obra de Ricoeur, mas jamais se engajou num diálogo com ele" (GRONDIN 1990, 121). É provável que Grondin desconheça o artigo que mencionamos na nota anterior (4), que reproduz um raro diálogo entre os dois autores.

${ }^{6}$ Pode-se mencionar, para não ser injusto com Gadamer, um artigo que se intitula "La hermenéutica de la sospecha". Embora Gadamer associe essa ideia à hermenêutica de Paul Ricoeur, o texto trata da relação entre retórica e hermenêutica. A suspeita tem uma relação com a retórica, e foi no protestantismo que ocorreu um primeiro momento de inflexão entre retórica e hermenêutica. A menção a Ricoeur nesse artigo não tem relação com o que Ricoeur entende por hermenêutica da suspeita.
} 
ele.

A orientação que seguiremos em nossa exposição procura cruzar as posições de cada um dos autores sem a pretensão de reconstruí-las em sua gênese teórica. Direcionamo-nos pontualmente aos aspectos em litígio, apoiando-nos também em alguns dos principais comentaristas de cada lado, alguns tomam partido em relação a um ou outro autor. Na segunda parte, procuramos distinguir sete aspectos principais que concorrem para delimitar as posições hermenêuticas dos dois pensadores em suas convergências e divergências. Na terceira parte, nos posicionamos em favor de um dos interlocutores em litígio, assumindo primeiramente uma posição de ruptura com a hermenêutica das tradições de Gadamer, a partir da posição mais radical de Hans Ineichen, e não já por meio da atitude conciliadora da hermenêutica de Ricoeur. A polêmica com Ineichen nos ajudará a discernir com mais acuidade o núcleo da divergência entre Gadamer e Ricoeur. Ineichen reivindica para a hermenêutica das tradições a necessidade da inclusão do diálogo com a linguística e a filosofia analítica, posição que converge em favor da hermenêutica crítica de Ricoeur. Ao darmos continuidade a esse intercurso crítico, apresentamos a contribuição específica de Ricoeur, que, ao nosso modo de ver, não foi enfatizada suficientemente por seus principais críticos, mas que pesa decisivamente no sentido de pensarmos uma revisão crítica da tradição hermenêutica.

\section{TÓPICOS DA RELAÇÃO ENTRE GADAMER E RICOEUR}

Para uma apreciação mais detalhada da relação entre os dois autores, optamos por dividir esta segunda parte em di- 
ferentes tópicos, que nos possibilitarão intervir com mais precisão sobre aspectos diferenciadores e convergentes. Tomaremos por base algumas orientações de Grondin (2008) em seu artigo "De Gadamer à Ricoeur. Peut-on parler d'une conception commune de l'herméneutique?", ao mesmo tempo em que aproveitamos para criticar aspectos de sua posição.

\subsection{PERCURSOS PARAlElos, HERANÇAS E INIMIGOS DIFERENTES}

O modo como Gadamer e Ricoeur se inscrevem na tradição hermenêutica possui "graus diversos e intenções diferentes" (GRONDIN 2008, 38). A hermenêutica de Gadamer procura fazer justiça à pretensão de verdade nas ciências humanas, que não se reduz à ideia de método (Dilthey) e, por isso, dirige-se ao modo de ser fundamental de um sujeito que procura se compreender a si mesmo (Heidegger), valorizando o papel dos preconceitos e a historicidade da compreensão. Ricoeur não abandona a herança metodológica de Dilthey e a matriz mais antiga da hermenêutica, enquanto método de interpretação de textos. $\mathrm{O}$ modelo do texto é o esquematismo principal da dialética de explicação e compreensão que impulsiona a hermenêutica para novas modalidades de mediação, como a história e o quase-texto da ação. É no centro desses desvios que ele reconhece a tarefa de arbitrar o conflito das interpretações rivais. Ricoeur desenvolve uma dupla concepção de hermenêutica: enquanto restauradora do sentido e como exercício de suspeita. Essa última dirige-se ao papel diferenciado que ele atribui à filosofia do cogito, uma vez que a hermenêutica da suspeita contribui para uma melhor compreensão do sujeito, liber- 
tando-o de suas ilusões. De fato, tal perspectiva não mantém nenhuma relação com a hermenêutica de Gadamer.

Podemos dizer que Verdade e Método é a obra magna de Gadamer, mas não podemos dizer o mesmo de Ricoeur. Sua concepção hermenêutica é desenvolvida numa dezena de obras e não se mantém unívoca, pois é enriquecida por vários desvios. Isso suscita uma dificuldade a mais, a de saber a qual Ricoeur nos referimos (GRONDIN 2008, 40). Não para menos Johann Michel $(2006,290)$ caracterizou os escritos de Ricoeur de "obra em movimento".

Eles chegaram à hermenêutica por caminhos e tradições diferentes. Gadamer por meio de Dilthey e Heidegger; Ricoeur pela tradição da filosofia reflexiva francesa que ele conhece por meio de Jean Nabert, Gabriel Marcel, Emmanuel Mounier, autores que não exercem nenhuma influência sobre Gadamer.

Como tradutor de Husserl na França, Ricoeur concebe a ideia de uma fenomenologia da vontade em Le volontaire et l'involontaire, com a intenção de fazer frente à Phénoménologie de la perception de Merleau-Ponty. Aí a hermenêutica está ausente. A virada hermenêutica só ocorre com a publicação da La Symbolique du mal. Nessa obra reconhece, face à tradição da filosofia reflexiva e da fenomenologia com seu programa radical de fundação, que não conhecemos o ego diretamente por introspecção, mas mediante interpretação dos códigos culturais que o constituem. Gadamer renuncia a qualquer tipo de filosofia reflexiva, mas se vincula a Ricoeur pela ideia de que em toda interpretação enriquecemos a compreensão que temos de nós mesmos.

Grondin $(2008,43)$, ao procurar diferenciar esta dupla concepção de hermenêutica, afirma que a questão que nor- 
teia cada um desses autores é, para Gadamer, "o que é que nos vem ao encontro quando nós compreendemos?", e, para Ricoeur, “como devemos interpretar?". Não estamos de acordo com o emprego do termo "como" nessa distinção, porque ele identifica a posição de Ricoeur com a postura metódica que Gadamer combate, colocando essas hermenêuticas em franca oposição. É verdade que Ricoeur dedica mais atenção aos métodos que mediatizam a interpretação, mas sua perspectiva não se reduz aos meios metódicos de atingi-la. Portanto, a tese de Grondin não faz justiça à ideia da "via longa" de Ricoeur, em que os diferentes recursos metodológicos visam, de modo semelhante a Gadamer, enriquecer a compreensão que temos de nós mesmos.

François Dosse $(1997,396)$ afirma que a evolução dos dois projetos "não pode ser pensada em termos de influências, mas muito mais como duas evoluções paralelas que se encontram sobre posições de grande proximidade”. De fato, o engajamento de Ricoeur na hermenêutica dos símbolos e na hermenêutica freudiana dá longos passos em sentido paralelo à de Gadamer, mas não convergente. Grondin concordaria com Dosse quanto à "evolução paralela", mas o termo "como" ("como devemos interpretar?"), utilizado para caracterizar a hermenêutica ricoeuriana, impossibilita-nos de ver a "grande proximidade" de ambos.

Eles possuem inimigos diferentes. Gadamer tem como inimigo a consciência metodológica das ciências do espírito (Dilthey), que ele enfrenta com as armas da ontologia heideggeriana. Pode-se dizer que sua hermenêutica opera "por trás do conflito das interpretações que possa preocupar nossos interesses científicos e metodológicos" (RICOUER; GADAMER 1991, 220).

$\mathrm{O}$ inimigo de Ricoeur é a postura anti-hermenêutica redutora do sentido, da psicanálise, do estruturalismo, da 
filosofia analítica, etc. $\mathrm{O}$ modo como Ricoeur enfrenta esSes adversários é tanto mais no sentido de acolhê-los criticamente do que refutá-los. Sua crítica se dirige ao reducionismo metodológico que impossibilita a articulação e o cruzamento entre diferentes jogos de linguagem. A hermenêutica opera medições e arbitra os conflitos, dentro das interpretações e métodos já praticados nas ciências humanas (RICOEUR; GADAMER, 1991, 222). Nesse particular podemos concordar com Grondin $(2008,45)$ que "parece bem arriscado se falar em uma concepção comum de hermenêutica”.

\subsection{A POSIÇÃO EM RELAÇÃO À DILTHEY}

Um aspecto importante a ser destacado é a posição dos autores em relação a Dilthey. Embora ambos retomem a problemática de Dilthey, para Gadamer ele é um adversário e, para Ricoeur, num certo sentido, um aliado.

A relação de Gadamer com Dilthey é central e crítica. Dilthey transfere o metodologismo vigente na ciência moderna para as ciências compreensivas do espírito. Esse ideal de ciência moderna não corresponde ao ideal humanístico mais antigo das ciências do espírito, que não procedem, como nas ciências da natureza, por "indução lógica, destacando regras e leis a partir do material recolhido", mas por meio da "indução artística", para a qual "não existem regras definitivas" (GRONDIN 1999, 182). As ciências do espírito viam no gosto ou senso estético um valor de conhecimento, não mero valor subjetivo, como em Kant. A subjetivação do juízo do gosto desacreditou o conhecimento das ciências do espírito, pressionado-as para a metodologia das ciências naturais. 
A primeira parte de Verdade e Método busca precisamente retomar esse debate. Gadamer apresenta a experiência do jogo como um modelo para o tipo de conhecimento que preside o senso estético e a racionalidade nas ciências do espírito. No jogo mantemos uma relação com o objeto em que o sujeito não domina a situação. Após repor esses pilares, procura reconstruir a pré-história das ciências do espírito ou da hermenêutica, na segunda parte de sua obra magna. Aí se defronta diretamente com o problema do historicismo e com a postura metodológica que Dilthey imprimiu ao conhecimento histórico. Gadamer considera que apenas a revalorização do mundo da vida por Husserl e a hermenêutica da facticidade de Heidegger estão em condições de afrontar a espécie de consciência alienante vigente nas ciências do espírito (GRONDIN 1999).

A obra de Gadamer foi recebida na França em tom "reativo" à ascendência de Heidegger e em polêmica com o pensamento “objetivo", o que contribuiu para situá-lo na esteira do pensamento de Dilthey sobre a polêmica entre explicação e compreensão. Nesse momento, "não foi suficientemente observado, nos diz Ricoeur, que Vérité et Méthode não começa pela questão da verdade nas ciências do espírito" ou contra o objetivismo, "mas pela experiência estética" $(1996,2)$. A hermenêutica se legitima fora do círculo objetivante das ciências do espírito e da querela do historicismo. Ao valorizar a experiência estética do jogo e do diálogo (o jogo de perguntas e respostas), a hermenêutica de Gadamer pode ser lida em continuidade ao diálogo de Platão e representa tanto uma réplica à metafísica escolástica quanto ao idealismo alemão, e em menor grau a Dilthey, como foi a leitura de outrora, da qual Ricoeur também foi devedor. 
Podemos resumir a três problemáticas principais a adesão crítica de Ricoeur a Dilthey: o lugar da subjetividade no círculo da apropriação do sentido do texto, que em Ricoeur pertence ao leitor, e não ao autor (Dilthey) - Gadamer também concordaria -; a superação do dualismo entre explicação e compreensão e a ideia de via longa.

A hermenêutica romântica sustenta que o objetivo da interpretação é atingir a consciência dum outro sujeito, processo que se chama apropriação, como se concebe desde Schleiermacher. Dilthey observa que essa subjetividade se encadeia objetivamente nas obras históricas e compete a uma ciência compreensiva decifrar o sentido daquele que nelas se expressa. Gadamer não recai nesse núcleo psicológico do significado. Para ele é a "coisa" dita, enquanto se manifesta como estranha, que pode ser apropriada, num processo de "fusão de horizontes". Porém, para esses autores, o objetivo da hermenêutica é "recobrar a consciência original perdida, tornando o passado contemporâneo de nossa compreensão atual” (KEARNEY 2004, 57). É nesse sentido que Ricoeur lança sua suspeita principal: "é uma questão de saber se a hermenêutica de Gadamer ultrapassou verdadeiramente o ponto de partida romântico da hermenêutica" (RICOEUR 1986, 108).

Ricoeur, por sua vez, procura reconstruir o círculo compreensivo enfrentando o debate epistemológico mais proeminente. Considera que modelos nomológicos ou explicativos, tais como o estruturalismo, a linguística, a filosofia analítica, a psicanálise, etc., podem ser trazidos para dentro do círculo compreensivo das ciências históricohermenêuticas. Nesse sentido, pretende superar a epistemologia dualista de Dilthey entre explicar e compreender, sendo esta a meta principal de "todo seu projeto filosófico" 
(DOSSE 1997, 399). Meu argumento, nos diz Ricoeur (1991, 226) "é que a compreensão sem explicação é cega tanto quanto a explicação sem compreensão é vazia”. Nesse objetivo Ricoeur não encontra em Gadamer um aliado.

A hermenêutica de Ricoeur procura seguir a via longa do diálogo com as ciências. Tal intento tem sua raiz em Dilthey, para quem a compreensão não visa desvendar a alma do poeta, os processos internos ao sujeito - segundo a leitura diltheyana de Schleiermacher -, mas a vida que se exterioriza e seu encadeamento (Zusammenhang) por meio das obras ${ }^{7}$. Ou seja, compreendemos pelo desvio, da via longa da decifração dos signos e das obras. Ricoeur aprofunda esse desvio, preservando a ideia epistemológica da hermenêutica: da compreensão como um modo de conhecimento (Dilthey), e não apenas como um modo de ser (Heidegger). Pretende uma articulação dialética entre epistemologia e ontologia, sob pena de iniciar um processo de pluralização do projeto hermenêutico, em que o processo de desregionalização decorre de diálogo itinerante com o "outro".

\subsection{A RELAC̣ÃO DiSTINTA EM RELAC̣ÃO A HEIDEGGER}

A concepção de via longa da hermenêutica ricoeuriana é uma espécie de réplica à "via curta" representada pela ontologia fundamental de Heidegger, que substitui a questão sobre as condições pelas quais podemos compreender um texto, a história, etc., ou seja, substitui a prática da compreensão ou interpretação no âmbito das ciências (derivado) pela questão o que é um ser cujo ser consiste em compre-

\footnotetext{
${ }^{7} \mathrm{O}$ empreendimento hermenêutico de Dilthey continua psicológico, uma vez que para ele a interpretação não se dirige "àquilo que diz o texto, mas aquele que nele se expressa" (RICOEUR 1986, 95, grifos do autor).
} 
ender (fundamental). Em 1965, quando Ricoeur faz essa consideração no texto Existence et hermenéutique ${ }^{8}$, não evocou Gadamer. O certo é que ele não se enquadra numa ontologia direta ("via curta") do Dasein, que procura explicitar os existenciais da compreensão (decadência, historicidade, etc.), pois retoma o caminho aberto por Dilthey de diálogo com as ciências do espírito. Se a ideia de "via curta" não se aplica a Gadamer, tampouco a ideia de "via" pode ser atribuída a sua hermenêutica filosófica (GRONDIN 2008, 47 49), uma vez que essa ideia sugere, em Ricoeur, uma perspectiva de diálogo franco com as ciências humanas e o consequente conflito de interpretações que elas impõem à tarefa hermenêutica.

Gadamer, ao procurar levar adiante a ontologia da compreensão para o diálogo com as ciências históricas, aprofunda o círculo romântico dessa ontologia, encaminhando sua hermenêutica para a reabilitação do preconceito, da tradição e da autoridade. Amplia, assim, junto com seu mestre Heidegger, a ruptura entre filosofia e ciência em prol da tentativa de resgatar uma filosofia prática no sentido aristotélico. Ricoeur também persegue este objetivo de uma filosofia prática, e até mesmo de uma ética, em seu último período, mas orienta-se em sentido contrário a esta virada ontológica da hermenêutica, pois concebe a posição metodológica como algo produtivo, não como alienação. Tais escolhas permitem a Ricoeur forjar a hipótese de leitura disjuntiva da obra de Gadamer (Verdade ou Método).

Jean Greisch $(2001,140)$ aponta duas razões principais que explicam porque a hermenêutica de Ricoeur não aderiu à virada ontológica que Heidegger e Gadamer imprimi-

\footnotetext{
${ }^{8}$ Posteriormente publicado em Le conflit des interprétations (1969, 7-8).
} 
ram à reflexão sobre a compreensão. A primeira, nos diz, "é a recusa de sacrificar o conceito 'exegético' de interpretação sobre o altar de uma ontologia da compreensão”. Heidegger só consegue conferir um estatuto ontológico à compreensão (Verstehen) e interpretação (Auslegung) expulsando o conceito de "técnica" da interpretação do campo da reflexão filosófica. Não é a explicação que Ricoeur pretende desocultar na hermenêutica de Heidegger, mas o conceito de interpretação. $\bigcirc$ que está em jogo em Ricoeur não é somente a reabilitação da possibilidade geral do paradigma hermenêutico dos textos, ou ainda, como em Dilthey, a compreensão do mundo histórico pelas ciências do espírito, mas um problema que não tem equivalente em Heidegger e Gadamer: trata-se, segundo Greisch $(2001,140)$, da "possibilidade de arbitrar o conflito das hermenêuticas rivais". O próprio Ricoeur confessa, em uma de suas entrevistas, que o que o distancia da hermenêutica de Gadamer é este ter concebido o campo hermenêutico como um campo conflitual, ao invés da perspectiva de Gadamer do acordo fundamental (RICOEUR 1990a, 19).

A segunda razão alegada pela qual a hermenêutica de Ricoeur não aderiu à virada ontológica não é o fato de Heidegger não ter elevado a linguagem a indicador do modo de ser, crítica que não lhe faz justiça, pois ele sempre considerou a linguagem um tema central. A principal divergência entre Heidegger e Ricoeur, aponta Greisch (2001, 140-141), não se reduz à alternativa simplista, a favor ou contra a linguagem, mas "a maneira como cada um concebe o estatuto e tarefa de uma filosofia da linguagem" no sentido semântico. Na terceira parte esclareceremos melhor a originalidade desse posicionamento da hermenêutica de Ricoeur. 


\subsection{A RELAÇÃO DA HERMENÊUTICA COM A FENOMENOLOGIA NOS DOIS PROJETOS}

Grondin discute o sentido da relação entre hermenêutica e fenomenologia nos dois autores. Considera que Gadamer propõe um desvio fenomenológico da hermenêutica, pois se desvincula do paradigma metodológico, uma vez que a hermenêutica ou "teoria do compreender próprio das ciências humanas" deve "descrever, fenomenologicamente, o modo como se produz a compreensão e a verdade nas ciências" fazendo "justiça a seu objeto" (GRONDIN 2008, 50). Ricoeur, por sua vez, fala de um enxerto da hermenêutica na fenomenologia, ou de um desvio hermenêutico da fenomenologia, uma vez que "seu projeto sempre foi este de uma descrição do fenômeno essencial", o do "esforço por existir" (Spinoza) que se dirige, em suas últimas obras, para uma antropologia do homem capaz, a "reapropriação pelo ego de seu esforço para ser" (GRONDIN 2008, 51). O caminho para compreender quem somos não se cumpre por intuição direta, se conquista por meio da mediação dos signos e obras da cultura que se dão à interpretação. "A hermenêutica é assim um adjetivo que vem qualificar a fenomenologia" (GRONDIN 2008, 52). Como nos informa Ricoeur (apud ESQUIROL 1991, 18):

Comecei minha carreira filosófica no quadro da fenomenologia alemã. De Husserl fui também tradutor. O que me aproximou da fenomenologia foi a descrição da experiência vivida; e o passo da fenomenologia à hermenêutica se realizou quando vi que esta descrição da experiência vivida não podia fazer-se diretamente, senão através de símbolos, às vezes de mitos, e sempre de interpretações.

O que a obra de Gadamer influenciou decisivamente Ricoeur, nos diz Dosse (1997, 394), foram suas teses contra o idealismo do programa fenomenológico, que Ricoeur veio 
a chamar de enxerto hermenêutico na fenomenologia. Grondin $(2008,53)$ considera, além disso, que a hermenêutica de Ricoeur permanece mais fenomenológica que metodológica, aquém do que ele próprio admitiria, pois não conseguiu resolveu os problemas metodológicos que reprova em Heidegger e Gadamer. Gostaríamos de deixar sem resposta esta questão aqui para enfrentá-la adiante quando comentarmos a posição específica de Ricoeur (seção 3.2).

\subsection{UMA RESPOSTA DIFERENTE AO DESAFIO DA HISTORICIDADE}

Tanto Gadamer quanto Ricoeur concebem a historicidade como uma condição inultrapassável da compreensão de si, que não conduz ao relativismo. Dosse (1997) ressalta como principal ponto de convergência entre ambos, a ideia de tradição como tradição viva e a ideia da linguagem como diálogo. Gadamer $(1998,477)$ admite que somos conduzidos por uma tradição e não podemos renunciar aos preconceitos, apenas discernir quais deles atuam na compreensão. O trabalho da história efetua certa triagem dos preconceitos, eliminando aqueles que são deformantes. Para Grondin (2008, 56), Gadamer "insiste demais sobre o serafetado-pela-história”. Ricoeur (2000), por sua vez, acentua também o caráter deformante da história e da tradição: a ideologia e utopia na dinâmica de efetuação da identidade coletiva; a matriz crítica da história sobre a memória; o esquecimento (l'oubli) que perpassa história e memória, etc. A história aparece mais como mestra da vida do que como instância que interfere na compreensão de si. Resgata assim um tanto de iniciativa diante da história que nos determina. Verifica-se aqui o acento sobre a dimensão política da ação 
histórica do sujeito, engajado na sociedade, que resiste às injustiças. Há em Ricoeur uma tensão crítica na recepção da história e não apenas um pathos da tradição.

\subsection{POSIÇÃO FACE À FILOSOFIA REFLEXIVA}

Gadamer, em combate com o idealismo, fala dos limites da filosofia da reflexão. Concebe a subjetividade como um "espelho deformante" (GADAMER 1998, 416). Ricoeur, por ter lido Freud, não desconsidera essa marca deformante da subjetividade, mas sublinha a "promessa de autonomia" consubstancial à filosofia reflexiva. Ricoeur parte de uma posição diferente em relação à hermenêutica alemã, admite uma visão alargada do cogito, que passa pela crítica de suas ilusões. Como nos diz Dosse (1997, 397), "a tarefa da filosofia permanece sendo a compreensão de si, mas ao preço de um trabalho de desapropriação e descentramento". Gadamer, ao deslocar a questão da compreensão da esfera psicológica - ainda presente em Dilthey - para o terreno da historicidade, evita toda e qualquer posição do cogito.

Ricoeur não opõe filosofia reflexiva e hermenêutica, uma vez que o cogito só pode ser recuperado por meio dos signos, obras e atos. Nunca se desvinculou da filosofia reflexiva, embora tenha recusado a ideia de um conhecimento imediato de si mesmo: consciência imediata não significa reflexão. Da filosofia da subjetividade inaugurada por Descartes ele retira duas demarcações: que não há objetividade sem subjetividade e a manutenção da problemática do conhecimento de si mesmo.

Essas duas questões serão levadas a efeito em Soi-même comme un autre, obra em que Ricoeur retoma a problemática do cogito incorporando a riqueza das análises da filosofia 
analítica. O que ele veio a chamar "hermenêutica do si" procura fazer face ao cogito atemporal, neutro e epistemológico - que trata a ética como algo provisório (Descartes) -, pensado na primeira pessoa (ego) e colocado "sem confrontação com outro" ou sem "o complemento intrínseco da intersubjetividade" (RICOEUR 1990, 14). Ele prefere denominar essa hermenêutica do si de "filosofia prática", ou "filosofia segunda" "após o fracasso do cogito em se constituir em filosofia primeira” (RICOEUR 1990, 31).

A promessa de autonomia que Ricoeur imprime a sua hermenêutica, seguindo a tradição crítica da filosofia do cogito, diferencia significativamente os dois filósofos. Essa marca pode ser destacada no plano da filosofia política. De um lado, o engajamento de Ricoeur, desde a juventude nos movimentos sociais e religiosos, como socialista cristão, como pacifista e no personalismo; de outro, a desilusão política de Gadamer face à catástrofe nazista. Um dos últimos ensaios de Gadamer intitula-se: "A incompetência política da filosofia”. Há em Gadamer uma espécie de fatalismo histórico, que tem suas raízes na crítica da técnica de Heidegger (GRONDIN 2008, 56). Ricoeur não se resigna a essa espécie de fatalismo, do ser-para-a-morte ou do niilismo, porque concebe uma tensão produtiva entre pertença (finitude) e horizonte de expectativa, que nos permite avançar e melhorar.

\subsection{A QUESTÃO DA ONTOLOGIA}

A ontologia de Gadamer pode ser compreendida pelo adágio "ser que pode ser compreendido é linguagem" (1998, 687). Segundo Grondin (2008, 59), essa afirmação contempla duas teses, uma sobre a compreensão e outra sobre o 
ser: só compreendemos o mundo por meio da nossa linguagem; e, o sentido do ser só pode ser desenvolvido pela linguagem. Ricoeur não comentou esse adágio, mas estaria de acordo com o seu propósito, nós nos compreendemos por meio dos signos, símbolos e textos da cultura. Embora a linguagem carregue sempre alguma coisa que não é linguagem, como é o caso da metáfora e do símbolo, "basta que seja dito" (GRONDIN 2008, 60). Ricoeur está de acordo com essa universalidade da linguagem reivindicada por Gadamer.

A ontologia de Ricoeur não é uma ontologia de nossa condição linguística "é uma ontologia do homem capaz que possa fazer justiça a nosso esforço para existir" (GRONDIN 2008, 61). Ele parte da ideia aristotélica dos múltiplos significados do ser e enfatiza a concepção de ser como ato e potência - no lugar da noção de ser como substância aplicando-a, através de Spinoza (desejo de ser, esforço por existir) à ação humana. As diferentes capacidades do homem, falar, fazer, narrar, imputar, rementem à noção de ato e ao "agir fundamental". Mas o homem não é apenas potência de agir, também sofre a ação de "outro", por isso, a ontologia do ato e da potência se articula com a metafísica dos grandes gêneros do Sofista de Platão, "mesmo", "outro", etc. Assim, o homem é agente e sofredor, ipseidade e alteridade. Compreende-se que essa reapropriação da ontologia tradicional por Ricoeur - a exemplo de Heidegger -, e seu encaminhamento para a ética, fazem ecoar a intenção de Levinas face ao ocultamento e neutralidade da hermenêutica ontológica de Heidegger e Gadamer em relação às questões éticas da filosofia. A postura ontológica desses filósofos 
deriva da radicalização da posição de Nietzsche, para quem não há fato ou moral, mas apenas interpretações ${ }^{9}$. A hermenêutica do si de Ricoeur procura ser uma resposta diferente à polêmica do cogito e anti-cogito - de que Nietzsche duvida melhor do que Descartes. Ela coloca a ação no centro da abordagem hermenêutica (RICOEUR 1990).

\section{POR UMA HERMENÊUTICA CRÍTICA: SOB O OLHAR DE HANS INEICHEN E PAUl RicoeUR}

Ricoeur avalia a obra Verdade e Método de Gadamer segundo uma alternativa disjuntiva de leitura (verdade ou método): "ou pratica-se a atitude metodológica, sem perdermos a densidade ontológica da realidade estudada, ou praticamos a atitude de verdade, mas, então temos que renunciar à objetividade das ciências humanas" (RICOEUR 1986, 113). Por isso, pergunta-se como introduzir novamente a instância crítica na hermenêutica face à consciência de pertença histórica que recusa a distanciação, melhor dito, que recusa "o momento crítico interno ao movimento de apropriação" (DOSSE 1997, 399).

Não sabemos se Ricoeur fez inteira justiça ao título da obra de Gadamer por meio de sua leitura disjuntiva, uma vez que sua interpretação não está desconectada da história da recepção dessa obra na França, que destacou a polêmica com Dilthey. Nas conversas com François Azouvi e Marc de Launay, publicadas no livro La critique et la conviction (1995,

\footnotetext{
9 “Contra o positivismo que se detém no fenômeno, 'só há fatos', eu diria não, precisamente não há fatos, apenas interpretações. Não podemos constatar nenhum fato 'em si'; talvez seja um absurdo querer algo como isso. 'Tudo é subjetivo', dizeis vós: mas isso já é interpretação, o 'sujeito' não é algo dado senão algo inventado e acrescentado, algo posto por detrás. É em última instância necessário por ainda o intérprete detrás da interpretação? Já isso é invenção, hipótese” (NIETZSCHE 2006, 7 [60], 222).
} 
56), Ricoeur reconhece que na época em que estava em debate com o estruturalismo separou-se de Gadamer para procurar uma via intermediária entre crítica e hermenêutica. Isso lhe permitiu intervir na controvérsia entre Habermas e Gadamer, surgida na Alemanha em 1971, entre hermenêutica das tradições e crítica das ideologias. Nesse debate considera essas alternativas complementares, no sentido de "requerer cada um a escuta do outro" (DOSSE 1997, 400). Postula, então, a ideia de uma "hermenêutica crítica" que pretende articular experiência de pertença e distanciamento alienante.

Em Du texte à l'action, (1986, 369-387) ${ }^{10}$, Ricoeur resume a três momentos principais esse enriquecimento crítico da hermenêutica. Primeiro, o distanciamento não é uma degradação ontológica, mas um meio indispensável, uma condição da interpretação. Segundo, a hermenêutica deve renunciar à alternativa entre explicar e compreender. É preciso levar até as últimas consequências o processo de objetivação, como nos diz, "explicar mais é compreender melhor" (RICOEUR 1986, 25). Valoriza-se assim, o momento crítico das condições de possibilidade do dizer, que resulta numa relação mais produtiva entre filosofia e ciências, ao mesmo tempo em que procura desmascarar as pretensões que se ocultam no processo de objetivação por meio da suspeita. Terceiro, a compreensão não é um transporte da subjetividade no texto (hermenêutica romântica), mas a exposição de uma subjetividade face o texto. Ricoeur está de

\footnotetext{
${ }^{10}$ No grande perímetro do pensamento ricoeuriano que pode ser caracterizado como um pensamento em movimento, essa obra concentra alguns ensaios em que Ricoeur assume inteiramente o paradigma textual e narrativo, diferente da obra Le conflit des interprétations, ainda bastante dominada pelo fenômeno do duplo sentido e do símbolo. Em Du texte à l'action, Ricoeur também dá entrada ao problema da ação e da história que será decisiva na sua última fase, iniciada com os três volumes de Temps et recit e Soi-même comme un autre.
} 
acordo com Gadamer em privilegiar a recepção da "coisa do texto" pelo leitor, contra a ideia de subjetividade escondida atrás do texto, mas critica a espécie de categorias do encontro e do diálogo à qual Gadamer submeteu tal relação. Ricoeur enfatiza a tripla "autonomia do texto" (em relação à situação original, ao destinatário e à intenção do autor), priorizando o fenômeno da escrita e da literatura e o modo crítico e objetivo pelo qual a linguística e semântica procuram ler e interpretar textos.

\subsection{A POSIÇÃO DE HANS INEICHEN SOBRE A HERMENÊUTICA DAS TRADIÇÕES}

A introdução de Hans Ineichen, que não faz parte direta da polêmica que estamos a discutir, se justifica em função da posição de ruptura que ele representa em relação à Gadamer, o que nos permite discernir com mais acuidade o núcleo da divergência com Ricoeur.

Hans Ineichen sublinha que a hermenêutica de Gadamer pretende ser uma filosofia da linguagem que se ergue em franca oposição à ideia da filosofia analítica tal como se configura desde Frege. Seguindo a mesma direção de Ricoeur, Ineichen considera que há uma conexão entre hermenêutica, filosofia da linguagem e crítica. Ressalta que a hermenêutica deve "ser completada pela filosofia analítica", pela crítica, e "não pode ignorar os diferentes conhecimentos das ciências empíricas" (1995, 183), para não permanecer numa "simples atitude de escuta da tradição" (1995, 193) - referência à hermenêutica de Gadamer.

Se tomarmos como tarefa primeira da hermenêutica a compreensão de textos, a questão que nos surge é saber se existe uma compreensão ou interpretação adequada de um 
texto. Dilthey e Max Weber sublinham que essa adequação só pode ser alcançada enquanto projeto de compreensão ou formação de hipóteses - em geral mais de uma ou várias. Não há texto que não tenha suscitado uma variedade de hipóteses interpretativas, e essa perspectiva só parece inadequada "se cremos que podemos abordar os textos sem pressuposição, de um ponto de vista a-histórico" (INEICHEN 1995, 186-187), o que não é o caso.

Falar de hipóteses implica a possibilidade de alcançar certa correção interpretativa. Nas ciências empíricas as hipóteses se distinguem da validação, no sentido de que os testes experimentais invalidam as hipóteses. No caso da interpretação, nos diz Ineichen $(1995,187)$, não há uma distinção tão estrita, porque "o que conta como argumento contra ou a favor de uma hipótese depende da própria hipótese". Essa dependência não impede que possamos falar de hipótese interpretativa. Essa é a questão crítica para a hermenêutica. É nesse sentido que Ricoeur (1986, 223 230), apoiando-se em E. D. Hirsch, concebe a interpretação como um processo de conjectura e validação.

A condição crítica de correção interpretativa ou validação é de suma importância, por exemplo, no caso da hermenêutica jurídica, na correta aplicação das leis. Verificamos tal exigência de validade quando um autor se exprime mal num texto; pressupomos que há uma compreensão melhor. Da mesma forma, ao falarmos de um discurso sistematicamente distorcido, a partir da psicanálise e da crítica das ideologias, pressupomos a validade de um discurso imune à distorção (INEICHEN 1995, 187-188).

Tal pretensão crítica não pode ser entendida apenas no sentido romântico, que obriga o intérprete a cavar o sentido original - atrás do texto -, seja da intuição do autor, ou o 
testemunho de outra época, que exprime mais do que o autor quis dizer. Nesse último aspecto vislumbra-se muito mais uma questão histórica do que crítica. A questão crítica examina "a validade das múltiplas pretensões de verdade dos textos" (INEICHEN 1995, 189). Por exemplo, queremos saber se as teses de Kant ainda são válidas. Não se trata de compreender o que o autor quis dizer, mas se tem valor o que ele disse. Para resolver isso também dispomos do saber científico. Essa exigência crítica não está distante da ideia da fenomenologia de Husserl. Nesse sentido, a hermenêutica de Gadamer se ergue sobre um domínio précientífico do saber: a experiência da arte, a tradição e o diálogo cotidiano, que se distancia do saber metódico e experimental das ciências.

Ineichen observa que a hermenêutica de Gadamer, por um lado, se transformou numa filosofia da linguagem, uma vez que compreender e interpretar são determinados pela linguagem. Por outro lado, observa que essa concepção de linguagem rejeita as teses da linguística contemporânea, sintaxe e semântica, porque tratam da linguagem como instrumento que visa à forma, e não à dimensão fenomenológica da relação íntima entre palavra e coisa. Para Gadamer, quando falamos dialogamos com as coisas, e não com a própria linguagem, como quer a análise linguística. Ineichen critica essa posição, considerando que há casos em que falamos com a própria linguagem: quando, por exemplo, procuramos pronunciar ou empregar uma palavra corretamente, ou quando percebemos que o sentido de uma palavra ou uma frase é incompreensível. Por isso, a concepção de Gadamer é para ele "inadimissível” e "decepcionante"; Gadamer não poderia falar em "história do conceito" (Begriffsgeschichte) sem se voltar para o conceito, ou 
seja, para a própria linguística. Ineichen admite que a crítica da redução formal da linguagem pela linguística é válida apenas em se tratando da sintaxe, que regula a relação entre os signos, não à semântica, enquanto estudo das relações entre signo e realidade. Porém, a concepção de linguagem de Gadamer rejeita a ambas como desvio instrumental. Para Ineichen, essa posição é contrária à própria ideia inicial da fenomenologia de Husserl, para a qual sintaxe e semântica ocupam um largo espaço no quadro de uma gramática universal, sendo que uma filosofia da linguagem sem sintaxe e semântica não teria valor algum $(1995,191-192)$.

A hermenêutica, para Ineichen, é impossível sem a semântica e a sintaxe, pois sem elas seria impossível interpretar uma palavra, uma frase ou um texto. É impossível compreender uma língua sem conhecer as regras de seu uso, as regras de sintaxe e semântica. Por isso, compreender uma língua não é uma questão de sentimento ou experiência. Embora o autor esteja longe de contestar que a compreensão cotidiana da linguagem é o ponto de partida de todo nosso agir e conhecimento, ressalta que por ser "lacunar e não sistemática" esse ponto de partida "permanece como tal até o instante em que negligenciamos os resultados da filosofia analítica e da linguística" (1995, 193). Ricoeur nos tem mostrado que a teoria estruturalista da forma literária nos ajuda a compreender melhor a poesia; a psicanálise, a compreender o sentido sistematicamente deformado. Da mesma forma, "a interpretação dos textos tem necessidade de conhecimentos decorrentes das diferentes ciências"; tem necessidade da crítica, que "só pode ser conduzida se for além de nosso saber cotidiano e se a completamos pelos resultados das ciências particulares" (1995, 193). E conclui Ineichen $(1995,193)$ : 
Se levamos a sério a tese da hermenêutica como filosofia da linguagem, não podemos renunciar nem ao conhecimento da filosofia analítica nem aos da linguística, ao menos que queiramos nos contentar com nossa compreensão fragmentária da linguagem. Mas é necessário completar a hermenêutica por uma crítica que examina as exigências de validade dos textos interpretados sobre a base de nosso saber atual. É assim que se poderá superar uma simples atitude de escuta da tradição.

\subsection{A CONTRIBUiçÃo ORIGINAl de PAUl Ricoeur PARA A TRADIÇÃO HERMENÊUTICA}

No livro Introdução à hermenêutica filosófica (1999)"1, Grondin apresenta e comenta os principais expoentes da tradição hermenêutica, sem incluir Paul Ricoeur. Tal silêncio talvez tenha sua justificativa no fato de Grondin não ter reconhecido em Ricoeur um pensamento hermenêutico autônomo, em virtude de ele ter priorizado uma filosofia do diálogo e o debate com seu outro. Num artigo de 1990, L’herméneitique positive de Paul Ricoeur (p. 121-137), acrescenta, no entanto, que tal ideia original é apenas apresentada em Temps et récit com a noção de "narração". Ricoeur (1990) não concorda com essa abordagem e, em sua crítica ao texto de Grondin, lamenta que ele não tenha valorizado sua contribuição específica para a tradição hermenêutica ${ }^{12}$.

François Dosse (1997, 404-405) (discípulo de Ricoeur) critica o posicionamento de Grondin (discípulo de Gadamer), que "atribui a Ricoeur apenas um lugar marginal no campo da hermenêutica contemporânea”. Para Dosse (1997, 401-402), a hermenêutica ricoeuriana renuncia "ao

\footnotetext{
${ }^{11}$ Texto original publicado em Alemão em 1991.

${ }^{12}$ Essa lacuna de Grondin tem sido reparada em alguma medida pelos diferentes artigos que ele tem escrito sobre o pensamento de Ricoeur e pelos importantes eventos dos quais tem participado.
} 
sonho romântico de uma unificação das interpretações em uma única hermenêutica englobante, mostrando, ao contrário, a pluralidade irredutível dos conflitos de interpretação”. Considera que a posição de Grondin não faz justiça à ideia da "via longa" em que as diferentes disciplinas metodológicas fazem avançar a hermenêutica num diálogo produtivo com as ciências humanas, colocando-a no centro do debate contemporâneo, sem mantê-la isolada na esfera ontológica e também pré-científica, em que Gadamer a situou.

Em vista disso, gostaríamos de destacar alguns aspectos teóricos importantes, nem sempre destacados por seus críticos, no que concerne à contribuição específica da hermenêutica de Ricoeur, além daqueles aspectos mencionados até aqui.

A posição original da hermenêutica de Ricoeur face à Heidegger e Gadamer e à tradição mais antiga da hermenêutica, não se deve ao fato mais aparente de Ricoeur retornar a centralidade da problemática dos textos da hermenêutica mais antiga, nem tampouco a inclusão da problemática narrativa, como ressaltou Grondin (1990), ou ainda da problemática reflexiva em relação à hermenêutica ontológica e outros aspectos a que nos referimos no decorrer desta exposição. De fato esses momentos são importantes, mas eles só fazem sentido, e este é o fator decisivo - e o motivo pelo qual incluímos a crítica de Hans Ineichen em nossa análise -, com base no conceito semântico e analítico de linguagem que Ricoeur sempre procurou vincular à sua hermenêutica e que falta a seu parceiro, como também ao intento mais antigo da hermenêutica.

Enquanto Gadamer parte de uma concepção ontológica da linguagem, que faz da linguagem o lugar privilegiado da experiência hermenêutica, segundo seu adágio lapidar "ser 
que pode ser compreendido é linguagem" $(1998,687)$, Ricoeur situa a linguisticidade da experiência num nível crítico em que a base semântica vem dar sustentação à hermenêutica, sem que essa intenção explicativa reduza a linguagem a objeto ou instrumento, como manifestou Gadamer, porque tal perspectiva, vimos, apenas se aplica à sintaxe ou semiótica. Ricoeur desenvolve uma abordagem bidimensional da linguagem, entre semântica e semiótica, herdada de Benveniste. Apenas a dimensão semântica da linguagem, em contraposição ao sistema sincrônico de signos da semiótica, possui evento e sentido e sentido e referência e carrega em si a problemática da inovação semântica. $\mathrm{O}$ símbolo, a metáfora e a narrativa apenas fazem avançar essa perspectiva de que a linguagem sempre fala do mundo, tem referência. A semântica da frase ou do discurso contempla uma estratégia sintética da linguagem, pois "uma frase é um todo irredutível à soma das partes" (RICOEUR 2003, 21), que carrega em si a problemática ontológica tão reclamada por aqueles autores. A hermenêutica trata de textos, de unidades mais longas do que a frase, mas tem seu sustentáculo nessa semântica da frase.

Esse conceito semântico e analítico da linguagem foi desenvolvido em diferentes trabalhos por Ricoeur. Em obras posteriores a La métaphore vive, ele se ocupa da narrativa e da análise da linguagem ordinária. Com isso, fez avançar a hermenêutica num diálogo mais sólido com as ciências humanas. Estende o arco hermenêutico dos textos para outros campos das ciências humanas, como a ação e a história, sobretudo porque o núcleo das considerações das ciências humanas se concentra em torno da análise da linguagem.

Voltamos àquela provocação de Grondin deixada sem 
resposta mais atrás, dando a ela um tom polêmico em função do resgate da originalidade da hermenêutica ricoeuriana. A questão de Grondin é que essa hermenêutica permanece mais fenomenológica que metodológica, aquém do que o próprio Ricoeur admitiria, pois não conseguiu resolver os problemas metodológicos que ele reprova em Heidegger e Gadamer.

A questão não é dizer se a hermenêutica de Ricoeur permanece mais fenomenológica ou metodológica. $\mathrm{O}$ contrário também poderia ser afirmado, basta ler La Métaphore vive, Temps et récit, ou Soi-même comme un autre, para se convencer do papel que as ciências da linguagem desempenharam em seu trabalho hermenêutico. A afirmação de Grondin pode ser verdadeira desde que se entenda que Ricoeur não deixa a metodologia na retaguarda da fenomenologia; ao contrário, a fenomenologia é uma dimensão possibilitadora do enfrentamento metodológico, que surge quando a análise da linguagem não consegue dar conta do plano da existência e da expressão. Ela aparece depois de se terem esgotado as possibilidades metodológicas, depois de "explicar mais", intenção que está em total acordo com a tarefa original da fenomenologia. Ricoeur pretende um cruzamento entre fenomenologia e análise da linguagem, que não poderemos desenvolver aqui.

Quanto à segunda afirmação de Grondin de que Ricoeur não conseguiu resolver os problemas metodológicos que reprova em Heidegger e Gadamer, tomada em sentido amplo, nenhum outro filósofo resolveu, em virtude de nossa própria condição limitada de pesquisa e de nossa condição de finitude, mas sair dessa condição é negar a própria perspectiva fenomenológico-hermenêutica. É claro que a crítica de Grondin se dirige a aspectos específicos, ao fato 
de Ricoeur não ter dado um organon para a inteligência dos textos; um fundamento para as ciências históricas; não ter arbitrado o conflito de interpretações rivais. Assim, lança uma pergunta derradeira: "Ricoeur verdadeiramente aportou uma solução a essas dificuldades?" (GRONDIN 2008, 53). Uma primeira questão é que nem todas essas questões traduzem o real objetivo ou motivo da hermenêutica de Ricoeur. Apenas a última questão é mais próxima do intento de Ricoeur. Ainda assim, devemos dizer que a cada questão levantada por Grondin poderia pontualmente ser respondida designando uma ou duas obras de Ricoeur. Por exemplo, um fundamento para as ciências históricas pode ser encontrado em La mémoire, l'histoire, l'oubli; um organon para a inteligência dos textos, poderíamos mencionar no mínimo três obras de trabalhos hermenêuticos mais importantes de Ricoeur; e quanto a arbitrar o conflito das interpretações rivais, Grondin parece desconhecer completamente o procedimento da hermenêutica ricoeuriana. Em quase todas as obras Ricoeur utiliza sua hermenêutica como uma forma de mediação face às diferentes disciplinas metodológicas que aprendeu a frequentar. Tomando como exemplo Soi-même comme un autre - onde denomina "hermenêutica" ao conjunto de suas análises do si - é ingênuo pensar que aí não há um esforço de Ricoeur para arbitrar o conflito de interpretações das diferentes abordagens do si por meio da análise semântica, da pragmática da linguagem, da teoria da ação, da narrativa e da ética, que rivalizam em torno da problemática da identidade. Em seguida, não é correto dizer que Ricoeur não tenha resolvido os conflitos hermenêuticos, a função da filosofia não é produzir conflitos. Justamente Ricoeur se opõe ao pluralismo radical dos jogos de linguagem - que preside a abordagem das diferentes dis- 
ciplinas metodológicas -, sua tarefa filosófica procura precisamente modalidades de integração.

Ricoeur nunca aceitou a ontologia como uma forma de imunizar a filosofia de sua relação necessária com a ciência. Dessa estratégia podemos retirar a máxima lapidar de sua filosofia hermenêutica: "explicar mais para compreender melhor" (RICOEUR 1986, 25). Mas a hermenêutica ricoeuriana, ao adotar a "via longa" para intervir no diálogo com as ciências humanas, transfere a tarefa ontológica para um horizonte longínquo. $\mathrm{O}$ tipo de questionamento que faz Grondin a Ricoeur é na verdade uma exigência ontológica que a hermenêutica de Ricoeur insiste em adiar, e que Grondin vislumbra a partir da hermenêutica de Gadamer de quem ele mesmo é discípulo.

\begin{abstract}
This paper presents the interface of two major representatives of contemporary hermeneutics, Hans-Georg Gadamer and Paul Ricoeur. Without intending to reconstruct the genesis of the theoretical positions in litigation, analyzes different aspects of it pointing to similarities and differences. After a brief introduction (first part), develops, in the second part, of more analytical form, the crossing of the positions of the interlocutors in seven main topics. The third part takes a moment of distancing itself from the hermeneutic tradition of Gadamer, through the critical mediation of Hans Ineichen and Paul Ricoeur. With them we support the necessity of hermeneutics of traditions include the idea of critique and dialogue with the linguistic and analytic philosophy, position which converges in favor of critical hermeneutics of Ricoeur which we intend to highlight it in their specific contribution in relation to the hermeneutic tradition of Gadamer.
\end{abstract}

Keywords: Hermeneutics; Gadamer; Ricoeur; Critical.

\title{
REFERÊNCIAS
}

DOSSE, François. Paul Ricoeur: Le sens d'une vie. Paris: La Découverte, 1997.

\section{ESQUIROL, Josep. Paul Ricoeur: Quién hace algo es la cuestión central. El ciervo, Barcelona, mayo 1991.}


GADAMER, Hans-Georg. Verdade e Método. Trad. de Flavio Paulo Meurer. Petrópolis: Vozes, 1998.

. La hermenéutica de la sospecha. Cuadernos Gris, v. 3, n. 2, p. 127-134, 1997.

- Auto-apresentação de Hans-Georg Gadamer. In: GADAMER, Hans-Georg. Verdade e Método II. Trad. de Enio Paulo Giachini. Petrópolis: Vozes, 2004.

GREISCH, Jean. Paul Ricoeur. L’itinérance du sens. Grenoble: Millon, 2001.

GRONDIN, Jean. L'herméneitique positive de Paul Ricoeur. $\mathrm{Du}$ temps au récit. In: BOUCHINDHOMME, Cristian; ROCHLITZ, Rainer. Temps et recit en débat. Paris: Du Serf, 1990a. p. 121137.

- Introdução à hermenêutica filosófica. Trad. de Benno Dischinger. São Leopoldo: Unisinos, 1999.

- De Gadamer à Ricoeur. Peut-on parler d'une conception commune de l'herméneutique? In: FIASSE, Gaëlle (Org.). Paul Ricoeur. De l'homme faillible à l'homme capable. Paris: Puf, 2008. p. 3762.

. Paul Ricoeur: réponses aux critiques. In: BOUCHINDHOMME, Cristian; ROCHLITZ, Rainer. Temps et recit en débat. Paris: Du Serf, 1990b. p. 201-205.

KEARNEY, Richard. Entre soi-même et um autre. In: REVAULT D’Allonnes, Myriam; AZOUVI, François. 
Cahiers de L'Herne-Ricoeur 2. Paris: Seuil, 2004. p. 41-71.

INEICHEN, Hans. Herméneutique et philosophie du langage. In: AA.VV. Paul Ricoeur. L'Heméneutique à l'école de la phénoménologie. Paris: Beauchesne Editeur, 1995. p. 183-194.

MICHEL, Johann. Paul Ricoeur une philosophie de l'agir humain. Paris: Du Cerf, 2006.

NIETZSCHE. Friedrich. Fragmentos Póstumos, Volumen IV (1885-1889). Trad. de Juan Luis Vermal y Joan B. Llenares. Madrid: Tecnos, 2006.

RICOEUR, Paul. Autobiografia intelectual. In: RICOEUR, Paul. Da metafísica à moral. Lisboa: Piaget, 1995.

. De la volonté à l'acte: Um entretien de Paul Ricoeur avec Carlos Oliveira. In: BOUCHINDHOMME, Cristian; ROCHLITZ, Rainer. Temps et recit en débat. Paris: Du Serf, 1990. p. 1736.

. Du texte à l'action. Essais d'herméneutique II. Paris: Seuil, 1986.

. La Critique et la conviction. Entretiens avec François Azouvi et Marc de Launay. Paris: Calmann-Lévy, 1995.

. Le conflit des interpretations. Essais d’herméneutique I. Paris: Seuil, 1969.

. Le retour de Gadamer. 1996, p. 1-2. Disponível em: http://www.fondsricoeur.fr/. Acesso em: 
ago. 2010.

. Soi-même comme un autre. Paris: Seuil, 1990.

RICOEUR, Paul; GADAMER, H-G. The conflict of interpretations: Debate with Hans-Georg Gadamer. In: VALDEZ, M. J. A Ricoeur reader: reflection and imagination. Toronto, Canada: University of Toronto Press, 1991. p. 216-241. 